\title{
72. PRODUCTS OF CHLOROPHYLL DIAGENESIS IN JAPAN TRENCH SEDIMENTS, DEEP SEA DRILLING PROJECT SITES 438, 439, AND 440
}

\author{
Earl W. Baker and J. William Louda, College of Science, Florida Atlantic University, Boca Raton, Florida
}

\section{INTRODUCTION}

Tetrapyrrole pigments isolated from sediments retrieved during Leg 57 include pheophytin- $a$, a myriad of chlorins, free-base deoxophylloerythroetioporphyrin (DPEP), as well as copper and nickel porphyrins. Their richness, both qualitatively and quantitatively, in chlorin tetrapyrroles affords a relatively complete study on the early diagenesis of chlorophyll. Our studies, coupled with those in the preceding chapter by Louda et al., point out the influence of pre- and postdepositional environments upon the mode of chlorophyll diagenesis. Formation of tetrapyrroles, collectively called "petroporphyrins," is seen to occur in only a limited set of environmental conditions (see Baker and Palmer, 1978). The more generalized route of chlorophyll diagenesis, at least in the ocean, results in removal of tetrapyrrole pigment, from the fossil record. Late diagenetic products, metalloporphyrins, are found to represent an extremely minor component of the tetrapyrrole assemblage in sediments studied from the Japan Trench.

The products of chlorophyll diagenesis isolated from Japan Trench sediments allow expansion of previous diagenetic schemes (Baker and Palmer, 1978; Triebs, 1936) and indicate directions for future studies.

\section{SAMPLES AND PROCEDURES}

Twenty-nine samples from Leg 57 were examined for tetrapyrrole pigments. Description and pigment yield are presented in Table 1.

Tetrapyrrole pigments were extracted from sediment samples with acetone:methanol $(9: 1, v / v)$ in a ball mill for periods of from three to five hours until extracts were colorless and exhibited no fluoresence under ultraviolet light. Crude extracts were concentrated in vacuo, transferred to ethyl ether, and washed several times with distilled water. Pigment yield was calculated from electronic spectra of crude extracts in tetrahydrofuran using $\alpha=63.7 \mathrm{l} \cdot \mathrm{g} \cdot \mathrm{cm}^{-1}$, for pheophytin $-a$

Tetrapyrrole pigment yield, given as $\mu \mathrm{g} / \mathrm{g}$ sediment, wet weight, and $\mu \mathrm{g} / \mathrm{g}$ sediment, dry weight, are given in Table 1. The latter calculation also utilized onboard analyses of sediment water content (see Carson and Bruns, this volume).

In the preceding chapter by Louda and others we defined an artificial Pigment Yield Index (PYI) as $\mu \mathrm{g}$ tetrapyrrole per gram of sediment, wet weight, divided by percentage of organic carbon, dry weight. Utilizing the onboard water content analyses, PYI values in Table 1 are defined and corrected for sediment water content, or PYI-dry. The correction to sediment dry weight clarifies trends in pigment loss with increasing depth of burial, especially in such highly consolidated sediments as those recovered from the landward slope of the Japan Trench (Site 440).

Preliminary purification of crude pigment isolates was by gel-permeation chromatography on Sephadex LH-20 with tetrahydrofuran as the mobile phase. Sephadex fractions were subjected to electronic spectroscopy in ethyl ether, and fractions containing enough pigment ( $>10 \mu \mathrm{g}$ ) for more detailed analyses were treated with diazomethane. Diazomethane treatment in the absence of base-to-pigment contact was shown in the preceding chapter to form only methyl esters and not to lead to further alteration of chlorins.

Initial chromatographic separation of pigments was on $2.5 \times 25-30 \mathrm{~cm}$ columns of $4 \mathrm{X}$ powdered sugar and developed with increasing percentages of acetone in petroleum ether $\left(30^{\circ} \mathrm{C}-60^{\circ} \mathrm{C}\right)$. Studies with known pigments showed that little if any separation of the methyl esters of the phorbin-type tetrapyrroles (e.g., pheophorbide, pyropheophorbide, 9-oxydeoxopheophorbide) is attained on this system. Sugar chromatography, of great value with chlorin-free acids (e.g., Strain, 1958), was used primarily to effect partial removal of nonpolar, early running hydrocarbons and to split the chlorin fraction into nonpolar and polar portions.

Separation of the chlorin fractions obtained after sugar chromatography was by chromatography on silica gel (100-200 mesh) columns developed with increasing percentages of acetone in petroleum ether. Extremely polar chlorins (e.g., chlorin-656) eluted from silica gel only with acetone:methanol $(1: 1, \mathrm{v} / \mathrm{v})$.

Free-base porphyrins were detected in both crude extracts and subsequent chromatographic fractions by the presence of a minor absorption band at approximately $620 \mathrm{~nm}$ in the electronic spectrum. Isolation was by extraction of ethereal pigment solutions with 3 to 5 per cent $\mathrm{HCl}$ (wt./v, aqueous). Purification of free-base porphyrins was accomplished with chromatography over neutral alumina (Grade III) developed with cyclohexane and cyclohexane:benzene $(1: 1, \mathrm{v} / \mathrm{v})$.

Chlorin-636 behaved much as a free-base porphyrin and was isolated from ethereal pigment solutions by extraction with 7 to 10 per cent $\mathrm{HCl}(\mathrm{w} / \mathrm{v})$. Chlorin-636 was purified by chromatography over silica gel (100-200 mesh) and required 3 to 4 per cent acetone in petroleum ether for elution.

Metalloporphyrins were detected by characteristic absorption at approximately 510 to $20 \mathrm{~nm}$ ( $\beta$-band) and approximately 550 to $560 \mathrm{~nm}$ ( $\alpha$-band) in the electronic spectra of early running fractions from chromatographic separations. Purification was attained by repéated chromatography over neutral alumina developed with 
TABLE 1

Sample Description and Tetrapyrrole Pigment Yield from Sites 438, 439, and 440

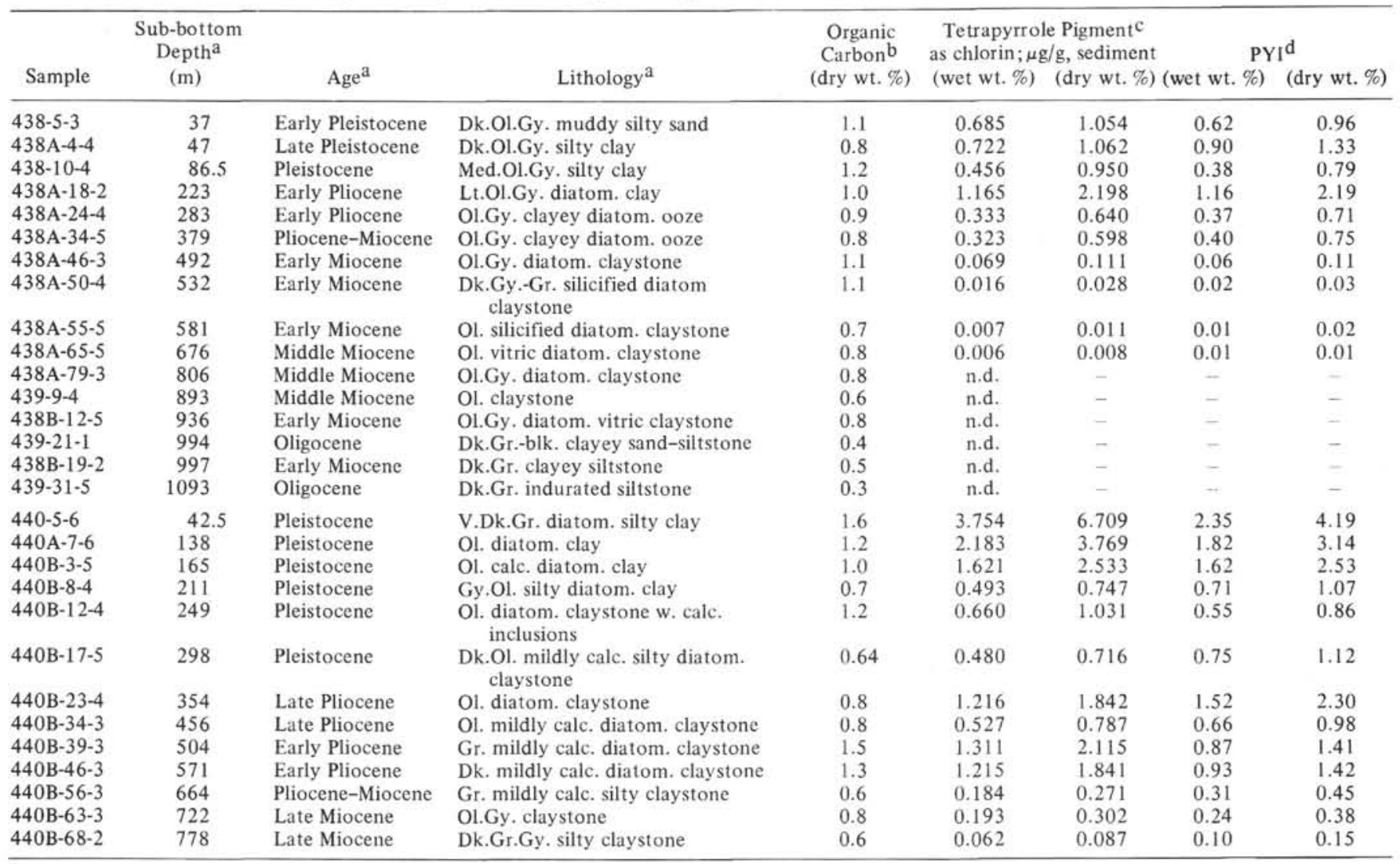

${ }^{\mathrm{a}}$ Data from Leg 57 (von Huene, Nasu, et al., 1977). Abbreviations: $\mathrm{V} .=$ very, Lt. $=$ light, Med. $=$ medium, Dk. $=$ dark, calc. $=$ calcareous, diatom. $=$ diatomaceous, $\mathrm{Gr} .=$ green, $\mathrm{Ol} .=$ olive, $\mathrm{Gy} .=$ gray, Blk. $=$ black.

$b_{K}$. A. Kvenvolden, 1979.

Total pigment, as chlorin, calculated using the specific extinction coefficient for pheophytin $a: \alpha=63.71 \cdot \mathrm{g} \cdot \mathrm{cm}^{-1}$.

${ }^{\mathrm{d}}$ Pigment yield index, defined in preceding chapter, this volume, Pt. 1, Louda et al., and in text.

benzene in cyclohexane and, alternately, trace tetrahydrofuran in petroleum ether (30-60 per cent).

Selected chlorin isolates were treated with trace sodium borohydride $\left(\mathrm{NaBH}_{4}\right)$ in ethanolic solution. $\mathrm{NaBH}_{4}$ is known to effect reduction only of carbonyl functions present as aldehyde, ketone, or acid chloride groups (Candlin and Rennie, 1973; Holt, 1959).

Isolates exhibiting pheophytin- $a$-like electronic spectra were chromatographed on thin layers of silica gel (Kodak $\# 6061,100 \mu \mathrm{m}$ ) developed with petroleum ether: acetone $(83: 17, v / v)$ concurrently with known pheophytin- $a$, methyl pheophorbide- $a$, and methyl pyropheophorbide- $a$.

Authentic chlorins were prepared from pheophytin- $a$ essentially by established techniques (cf. Fischer and Stern, 1940; Furhop and Smith, 1975). Structures of known compounds were verified by field (FD) and electron impact desorption (EID) mass spectrometry. FD and EID mass spectra were determined with a Varian CH-5 DF mass spectrometer interfaced to a DEC PDP $11 / 20$ data system (see Soltman et al., 1977; Holland et al., 1976).

Preliminary studies on the utility of high performance liquid chromatography (HPLC) in the analyses of tetrapyrrole mixtures derived from deep ocean sediments, suggested by the success of others (e.g., Hajibahim et al., 1978), were performed. Selected isolates were submitted to HPLC on a Laboratory Data Control (LDC) GLC-401 fitted with a variable wavelength detector using a $4.6 \mathrm{~mm} \times 25 \mathrm{~cm}$ column of $3-\mu \mathrm{m}$ silica (Spherisorb). Samples were dissolved with acetone:hexane $(1: 1, \mathrm{v} / \mathrm{v})$, injected in $20 \mu 1$ volume and eluted isocratically with acetone:hexane $(1: 9, \mathrm{v} / \mathrm{v})$. Alternately, stepwise gradient elution was employed using acetone:hexane mixtures controlled by a LDC Gradient Master. Solvent flow was 1.0-1.2 $\mathrm{ml} / \mathrm{min}$., giving an effective liquid pressure of approximately $1000 \mathrm{psig}$. Concentration tests with known methyl pheophorbide- $a$ showed that as little as $10 \mathrm{ng}$ of pigment can be easily detected.

Electronic spectra of tetrapyrrole pigments were determined in ethyl ether solvent for the range of 350 to $800 \mathrm{~nm}$ using a Perkin-Elmer \#575 spectrophotometer calibrated with holmium oxide and $0.1 \mathrm{mM} \mathrm{K}_{3} \mathrm{Fe}(\mathrm{CN})_{6}$.

Electron impact mass spectra were determined with a DuPont 491-BR mass spectrometer. Tetrapyrrole isolates were introduced via solid probe essentially as described previously (e.g., Baker et al., 1977, 1978). 
Purification of solvents, laboratory conditions, and preliminary sample handling have been described in the preceding chapter.

Structures and nomenclature follow the literature (e.g., Fischer and Stern, 1940; Seely, 1966).

\section{RESULTS AND CONCLUSIONS}

\section{Pigment Yield and Observed Trends}

The demise of tetrapyrrole pigment with increasing sub-bottom depth, or geologic age, within sediment profiled apparently indicates a major pathway of chlorophyll diagenesis. Hence degradation rather than preservation of the tetrapyrrole chromophore as such appears dominant in sediments retrieved during Leg 57.

Relating pigment yield to the organic carbon content of sediment, especially on a dry weight basis, now allows a much easier method in tracing trends and even rates of pigment loss from the fossil record.

Pigment yield data in Table 1 are presented graphically as Figure 1, wherein the pigment yield index (PYI), dry weight, is plotted versus depth sub-bottom. The majority of data fall into a rather well-defined curve, with two major loss rates (viz. slopes) becoming apparent. A rather rapid loss occurring in the upper 250 to 300 meters sub-bottom $(\triangle \mathrm{PYI}=-1.2 / 100 \mathrm{~m})$ is followed by a much decreased rate of loss below approximately 300 meters sub-bottom $(\triangle \mathrm{PYI}=-0.2 / 100 \mathrm{~m})$. These approximations are given only for sediments from Site 440 because of the influence of sand-rich terrigenous materi$\mathrm{al}$ in the Pleistocene strata and the added factor of subsidence at Site 438 (Site Reports, Sites 438, 439, and

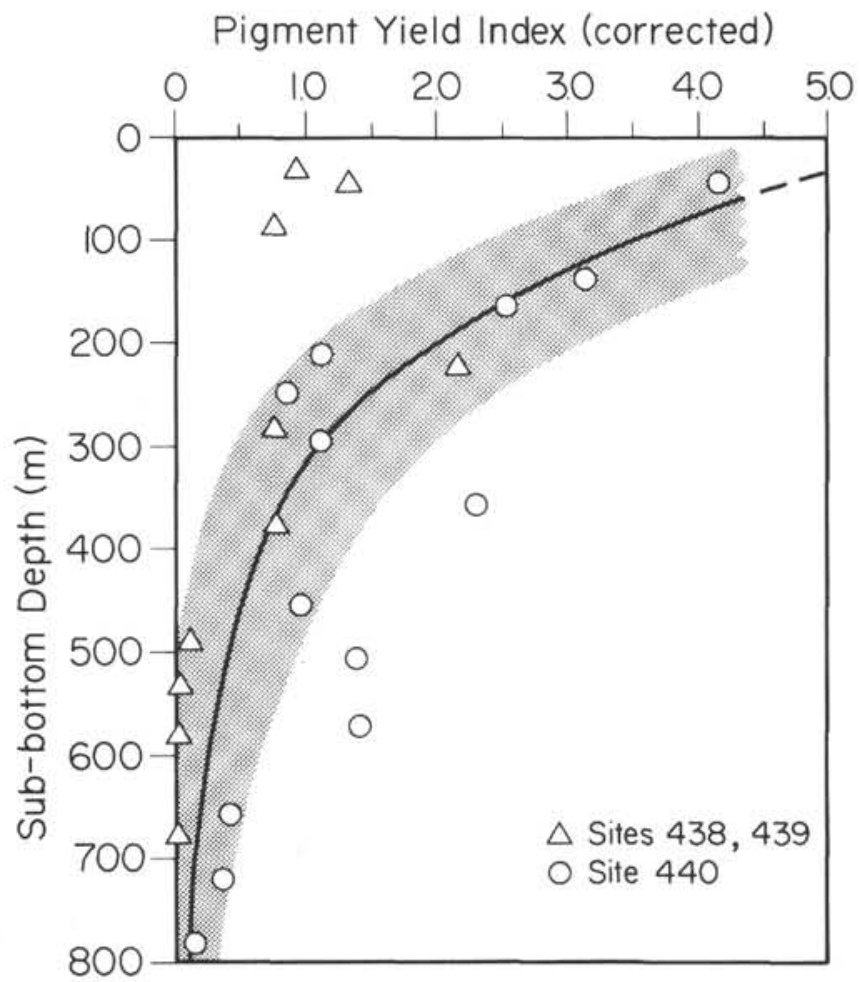

Figure 1. Pigment yield from Leg 57 sediment samples. (PYI is corrected to sediment, dry weight.)
440 , this volume, Part 1). This bimodal rate of pigment loss was noted for sediments from Sites 434 and 435 from Leg 56 (Louda et al., preceding chapter). In comparison of depth/age relationships throughout sedimentary sequences for Sites $434,435,436,438,439$, and 440 shows that the most overt change in rate of pigment loss with increasing depth of burial occurs in the region of the Pleistocene/Pliocene boundary (e.g., Sites 434 and 435 , approximately $100-150 \mathrm{~m}$, and Site 440 , approximately $300 \mathrm{~m}$ ). That this apparent change in the rate of pigment loss is a result of variant input about the Pleistocene/Pliocene boundary seems unlikely. Rather it appears to be the result of competing diagenetic reactions. That is, reactions leading to pigment demise occur at a faster rate for a certain period (e.g., Quaternary equivalency); then concurrent reactions leading to more thermodynamically stable species (e.g., defunctionalized chlorins, early porphyrins, and initial metallochelates) become dominant.

Studies of chlorophyll derivatives in surface sediments (i.e., 0-5 $\mathrm{m}$ sub-bottom) and throughout the water column have shown that the most drastic losses of chlorophyll and derivatives occur in the water column and the top 0 to $6 \mathrm{~cm}$ of sediment in both marine (Orr et al., 1958; Swain et al., 1964; Yentsch, 1965) and lacustrine (Kemp and Lewis, 1968; Koyama et al., 1968) environments. That the initial extremely rapid degradation of chlorophyll/pheophytin is related to oxidative processes is apparent from correlations to redox potential (Eh) (Kemp and Lewis, 1968; Koyama et al., 1968; Orr et al., 1958) and to the general classes of chlorin pigments isolated during the present study.

Tetrapyrrole pigments isolated from Leg 57 samples exhibited the electronic spectral data presented in Table 2 . The composition of tetrapyrrole pigment assemblages extracted from sediments retrieved at Sites 438 and 440 is given in Table 3 . Site 439 sediment samples yielded no tetrapyrrole pigments.

The previously noted (Baker et al., 1978; Baker and Smith, 1974; Louda et al., preceding chapter) trend for chlorin electronic spectra to undergo a hypsochromic (i.e., blue) shift with increasing depth sub-bottom is again observed in the present study. Plotting percentage of chlorins exhibiting red maxima at wavelengths greater than $664 \mathrm{~nm}$ versus depth sub-bottom (Figure 2) reveals that, with minor alterations, a relatively constant transition occurs. Extrapolation of Figure 2 to the sediment surface and the fact that 100 per cent of the chlorins exhibit red maxima greater than $664 \mathrm{~nm}$ implied input of primarily pheophytin. Deviations about this generated curve probably represent geologic occurrences, such as the slumping noted in the Pliocene-Miocene strata at Site 440 (see Site 440 chapter, this volume, Part 1), rather than discrete stages in diagenesis. This interpretation is based on the fact that the occurrence of intermediate chlorins is continuous and nonselective for any individual chlorin species (see Table 3 ). The presence of altered chlorins (purpurins) with bathochromically shifted red maxima might at first be thought to alter drastically the rate at which chlorin red maxima decrease in relation to depth. However, even with the generation of more highly conjugated species, such as 
TABLE 2

Spectroscopy of Tetrapyrrole Pigments Isolates from Leg 57 Samples and Selected Synthetic Chlorins

\begin{tabular}{|c|c|c|c|c|}
\hline \multirow{2}{*}{$\begin{array}{l}\text { Tetrapyrrole Pigment } \\
\text { Isolates }\end{array}$} & \multicolumn{2}{|c|}{$\begin{array}{c}\text { Electron Spectrum, } \\
\text { nanometers, ethyl ether solvent }\end{array}$} & \multirow[t]{2}{*}{ S/I Ratio ${ }^{a}$} & \multirow[t]{2}{*}{ I/IV Ratio } \\
\hline & & & & \\
\hline Pheophytin- $a$ & 410 & $506,535,610,667$ & $2.5: 1$ & $6.8: 1$ \\
\hline Pheophytin- $a$, post $\mathrm{BH}_{4} \mathrm{~b}$ & 396 & 598,652 & $4.9: 1$ & $3.5: 1$ \\
\hline Chlorin- 665 & 408 & $506,535,606,665$ & $3.7: 1$ & $4.7: 1$ \\
\hline Site 440 chlorin 663 & 406 & $503,534,608,663$ & $3.3: 1$ & $6.0: 1$ \\
\hline Site 440 chlorin 663 , post $\mathrm{BH}_{4}$ & 396 & $500, \quad 593,646$ & $4.9: 1$ & $3.7: 1$ \\
\hline Site 438 chlorin 663 & 407 & $503,534,608,663$ & $3.8: 1$ & $5.5: 1$ \\
\hline Site 438 chlorin 663 , post $\mathrm{BH}_{4}$ & 390 & $489, \quad 565,636$ & $5.1: 1$ & $1.8: 1$ \\
\hline Chlorin- 660 & 396 & 602,660 & - & - \\
\hline Chlorin- 660 , post $\mathrm{BH}_{4}$ & 396 & 600,648 & - & - \\
\hline Chlorin- 656 & 414 & $507,540,601,656$ & $6.5: 1$ & $7.7: 1$ \\
\hline Chlorin- 656 , post $\mathrm{BH}_{4}$ & 396 & $499, \quad 602,647$ & - & - \\
\hline Chlorin- 636 & 405.5 & $509,549,585,636$ & $9.4: 1$ & $2.2: 1$ \\
\hline Chlorin- 690 (altered chlorin) & 365,408 & $(505) 540(640) 690$ & - & - \\
\hline Altered chlorin $\# 1^{\mathrm{c}}$ & 408 & $(505)(545) \quad 692$ & - & - \\
\hline Altered chlorin $\# 2^{\mathrm{c}}$ & 404 & $502,542, \quad 684$ & - & - \\
\hline Tetrapyrrole- 586 & 396 & 586 & - & - \\
\hline Free-base (DPEP) porphyrin & 401 & $501(535) 567,620$ & - & - \\
\hline Metalloporphyrin $(\mathrm{Cu} / \mathrm{Ni})$ & $393-4$ & 520,556 & - & - \\
\hline \multicolumn{5}{|l|}{ Synthetic Chlorins } \\
\hline Pheophytin-a & 410 & $506,535,610,667$ & $2.3: 1$ & $5.1: 1$ \\
\hline 9-oxydeoxopheophytin- $a$ & 396 & $500, \quad 598,652$ & $3.9: 1$ & $3.0: 1$ \\
\hline Pheophorbide- $a, \mathrm{ME}^{\mathrm{d}}$ & 410 & $506,535,610,667$ & $2.5: 1$ & $4.0: 1$ \\
\hline 9-oxydeoxopyropheophorbide- $a, \mathrm{ME}$ & 396 & $500, \quad 598,652$ & $4.0: 1$ & $3.1: 1$ \\
\hline Pyropheophorbide- $a, \mathrm{ME}$ & 410 & $506,535,610,667$ & $2.3: 1$ & $5.3: 1$ \\
\hline 9-oxydeoxopyropheophorbide- $a, \mathrm{ME}$ & 396 & $500, \quad 598,652$ & $3.5: 1$ & $3.1: 1$ \\
\hline Pheophytin- $b$ & 412,435 & $525(555) 598,652$ & - & - \\
\hline Pheophytin- $b$, post $\mathrm{BH}_{4}$ & 401 & $504, \quad(600) 650$ & - & - \\
\hline Rhodin-g 7 & (409)426 & $515-35,600,654$ & - & - \\
\hline Rhodin- $\mathrm{g}_{7}$, post $\mathrm{BH}_{4}$ & 401 & $502(532) 603,652$ & - & - \\
\hline Purpurin-18, ME & 362,408 & $508,544,640,696$ & $2.5: 1$ & $9.4: 1$ \\
\hline Purpurin-18, ME, post $\mathrm{BH}_{4}$ & 402 & $503,534,615,666$ & $3.0: 1$ & $4.5: 1$ \\
\hline Purpurin-7, TME ${ }^{\mathrm{d}}$ & 400 & $503,543(630) 682$ & $3.8: 1$ & $3.8: 1$ \\
\hline Purpurin-7, TME, post $\mathrm{BH}_{4}$ & 398 & $500,530,610,663$ & $3.1: 1$ & $4.0: 1$ \\
\hline Chlorin- $e_{6}$, TME & 398 & $500,534(600-15) 666$ & $3.4: 1$ & $3.8: 1$ \\
\hline Deoxomesopyropheophorbide- $a, \mathrm{ME}$ & 390 & 590,638 & $4.1: 1$ & $3.8: 1$ \\
\hline Dioxydeoxophylloerythrin & 401 & $505,541,581,636$ & $4.7: 1$ & $4.6: 1$ \\
\hline 7-oxo-octaethyl chlorin & 408 & $511,550,590,642$ & $4.7: 1$ & $4.2: 1$ \\
\hline Dihydro-DPEP & - & $\begin{array}{r}495 \text { (approx.) } \\
585,640 \\
\text { (approx.) }\end{array}$ & - & $c a .2 .0: 1$ \\
\hline
\end{tabular}

${ }^{\mathrm{a}} \mathrm{S} / \mathrm{I}$ and I/IV, ratio of absorbancies: Soret (S) absorption taken directly, Bands I-IV corrected for background.

${ }_{\mathrm{C}}^{\mathrm{Post}} \mathrm{BH}_{4}$ refers to sodium borohydride reduction product (see text).

c) Altered chlorins \#1 and \#2 isolated by HPLC (see text).

ME, methyl ester; TME, trimethyl ester.

e From Blummer and Omenn, 1961.

the purpurins, in an oxic environment, subsequent reductive processes established with greater depth of burial would still be operative and lead to essentially the same overt shifts of red maxima in electronic spectra, though possibly shifting the curve upward. The shift in electronic absorption to higher energy (hypsochromism) has been attributed to reduction of ring-conjugating groups (cf. Baker and Smith, 1973; Hodgson, 1973; Smith and Baker, 1974) and appears to retain validity. The possibility of concerted reduction, hydrolysis, dehydration, decarboxylation, and the like needs further investigation, for not only will reduction of a con- 
TABLE 3

Approximate Composition (\%) of Tetrapyrrole Pigment Isolates from Sites 438,439 , and 440

\begin{tabular}{|c|c|c|c|c|c|c|c|c|c|c|}
\hline Sample & 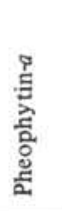 & $\begin{array}{l}\widetilde{0} \\
\frac{0}{0} \\
\frac{1}{3} \\
\frac{1}{0} \\
\frac{0}{0}\end{array}$ & 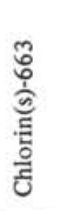 & 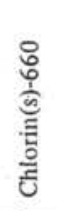 & 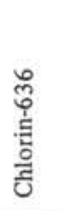 & 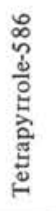 & 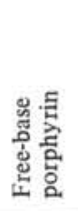 & 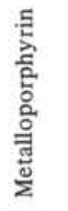 & 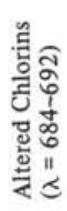 & 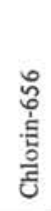 \\
\hline $38-5$ & - & - & 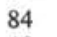 & - & 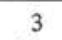 & - & ind. & - & 13 & - \\
\hline & - & - & & & 13 & - & & - & & - \\
\hline & - & 3 & $47 x$ & & 11 & - & + & - & & - \\
\hline & - & - & 70 & - & 1 & ind. & - & - & & - \\
\hline & - & - & - & 4 & - & ind. & - & - & & - \\
\hline & - & - & - & & 1 & - & - & - & 39 & - \\
\hline & - & - & - & ++ & - & ind. & - & ind. & ++ & - \\
\hline & - & - & - & + & - & + & - & + & 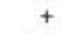 & - \\
\hline & - & - & - & t & - & ind. & . & + & ind. & - \\
\hline $38 \mathrm{~A}$ & - & - & - & + & - & - & - & ind. & - & - \\
\hline 40 & $23 \mathrm{x}$ & 18 & 30 & 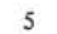 & 1 & - & - & - & 24 & - \\
\hline & & 5 & 44 & & - & - & & . & - & 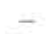 \\
\hline & 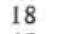 & 12 & 19 & 20 & I & - & - & - & 22 & $8 \mathrm{x}$ \\
\hline & 4 & 1 & 34 & 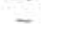 & - & - & - & - & 8 & 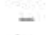 \\
\hline & 3 & & 35 & & - & - & - & - & 12 & 3 \\
\hline & 30 & 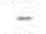 & 5 & 5 & - & - & - & - & & - \\
\hline & 3 & 11 & & & ind. & ind. & - & + & & - \\
\hline & 19 & - & 57 & 20 & - & - & - & + & 4 & - \\
\hline & - & 8 & $67 \mathrm{x}$ & 6 & 2 & ind. & & + & 17 & - \\
\hline & & - & $82 \mathrm{x}$ & $\sigma^{2}$ & 1 & + & inc & 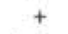 & 8 & - \\
\hline & - & - & - & + & - & - & - & ind. & - & 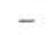 \\
\hline & - & - & 33 & $66 x$ & - & - & - & 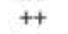 & - & + \\
\hline $440 \mathrm{~B}-68-2$ & - & - & - & - & - & - & - & ind. & 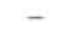 & \\
\hline
\end{tabular}

Note: Values are normalized, using absorption values at chlorin red maxima. Equal extinction of chlorin species is assumed. ind. = indicated from spectra of mixtures;,$+++=$ present, relative downhole relationship; $x=$ positive reaction with borohydride ethanol. Only selected isolates were tested for carbonyl functions.

jugated group lead to hypsochromic shifts in absorption spectra, but complete removal of these same functions will also.

The individual stages (reactions) of the diagenesis of sedimentary chlorophyll (viz. pheophytin) and the sequence in which they occur are easily interpreted by examining Table 3. As first postulated by Triebs (1936), the transformation of pheophytin- $a$ through a series of more and more highly reduced (defunctionalized) chlorins leading to the generation of free-base porphyrins (aromatization) which then complex with metal (chelation), forming metalloporphyrins, can be discerned in the downhole tetrapyrrole sequences, especially for Site 440. Altered chlorins and chlorin-656 do not necessarily fit into the reductive diagenetic scheme and are thus isolated in their presentation in Table 3. The occurrence of free-base DPEP in the Pleistocene sediments of Site 438 is attributed to sediment reworking and does not indicate early generation of free-base porphyrin.

The preservation of conjugated carbonyl functions in chlorin tetrapyrroles was traced by treating selected isolates with borohydride. Reduction of individual chlorin species is discussed in the following section. Chlorins containing conjugated carbonyl groups are present in Site 440 sediments from 42 to 722 meters sub-bottom. These findings show preservation of Miocene-formed carbonyl functions and indicate that geochemical reduction of these groups is not as facile as one might expect.

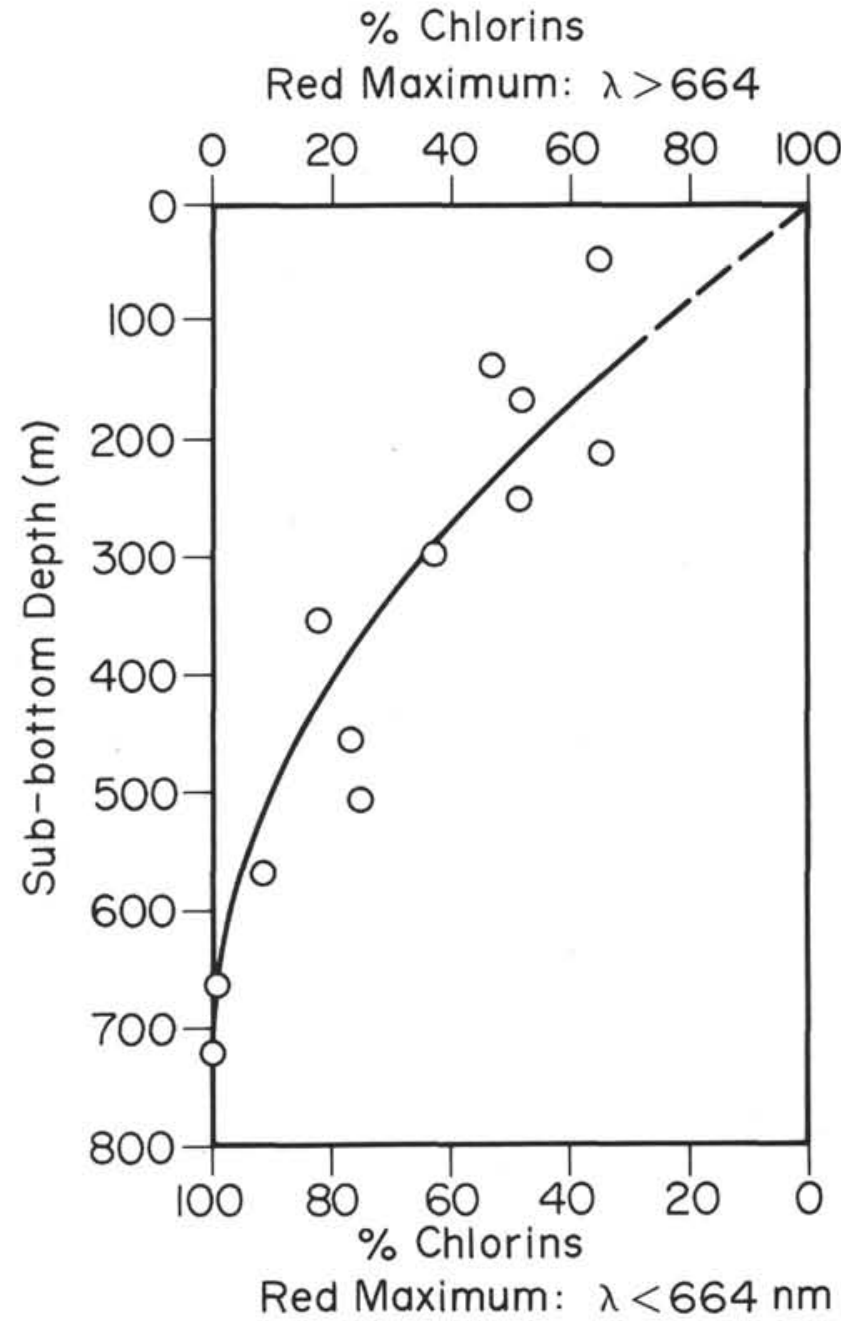

Figure 2. Chlorin electronic spectral shifts with increasing sediment depth sub-bottom, Leg 57, Site 440.

\section{Tetrapyrrole Pigments}

\section{Pheophytin- $a$}

Pheophytin- $a$ eluted as a nonpolar band from columns of sugar, alumina, or silica with 1 to 3 per cent acetone in petroleum ether. Activated silica gel proved to be the best adsorbant for purification of pheophytin$a$ from semipurified (i.e., Sephadex, sugar) fractions, allowing the pigment to be retained while unidentified blue fluorescing hydrocarbons were eluted with petroleum ether (PE) and 1 to 2 per cent acetone in PE. Pheophytin- $a$ then eluted as a compact olive green band with 3 to 5 per cent acetone in PE. Thin-layer chromatography on silica gel developed with petroleum ether: acetone $(85: 15, \mathrm{v} / \mathrm{v})$ resulted in the following $R_{f}$ values for pheophytin- $a$ isolates and authentic pheopigments: Site 440 pheophytin- $a, R_{f}=0.42-0.44(\bar{x}=0.424)$; pheophytin- $a, R_{f}=0.42-0.43(\bar{x}=0.423)$; pheophorbide- $a$ methyl ester, $R_{f}=0.20$; pheophorbide- $a$ free acid, $R_{f}=0.01$; pyropheophorbide- $a^{\mathrm{E}}$ methyl ester, $R_{f}=$ 0.27 . 
Pheophytin- $a$ isolated from Sample 440-5-6 and authentic pheophytin- $a$ were treated with sodium borohydride. Co-thin layer chromatography of the reduction products (9-oxydeoxopheophorbide- $a$ phytyl ester) on silica gel developed with petroleum ether: acetone (3:1, $\mathrm{v} / \mathrm{v})$ yielded $R_{f}=0.56-0.57$ for both pigments.

Electronic absorption spectra for Site 440 pheophytin- $a$ and the oxydeoxo pigment obtained by borohydride reduction (Table 2; Figure $3 a$ ) are identical to known pheophytin- $a$ and 9-oxydeoxopheophytin- $a$, respectively.

Pheophytin- $a$ isolated from Leg 56 (preceding chapter) Sample 434-1-3 (Pleistocene, $4 \mathrm{~m}$ sub-bottom) was further verified during the present study according to the desiderata just outlined.

Pheophytin- $a$ was verified in sediments from the midslope terrace of the Japan Trench from 4 (Sample 434-1-3) to 456 (Sample 440B-34-3) meters sub-bottom and was absent from sediments from Sites 438 and 439.

Pheophytin- $a$ most likely exists as dihydrophytol pheophorbide- $a$, generated by the reduction of the 2,3-double bond of the phytyl moiety. Previous studies (Baker, 1970; Baker and Smith, 1973) have shown the presence of $\mathrm{m} / \mathrm{e} 872$, corresponding to the mass of dihy-
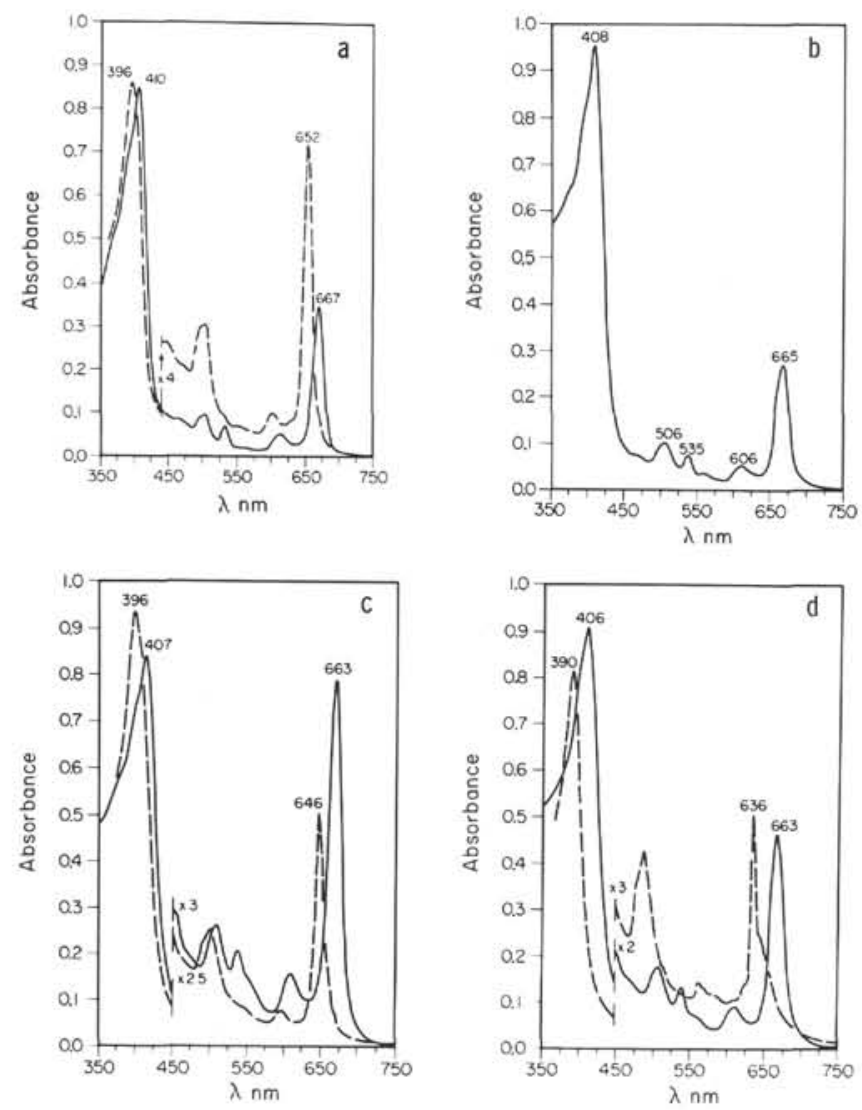

Figure 3. Electronic absorption spectra of chlorins isolated from Leg 57 samples. a. Pheophytin-a; b. Chlorin-665; c. Site 440 Chlorin-663; d. Site 438 Chlorin-663. (Solid lines $=$ native pigment; broken lines = the product of borohydride reduction [ethyl ether solvent].) drophytol pheophorbide- $a$, in mass spectra of chlorins from deep sea sediments.

Unidentified chlorin tetrapyrrole isolates are specified by the position of the red maxima of electronic spectra as recorded in ethyl ether solvent. Altered chlorins are grouped together for the present.

\section{Chlorin-665}

This pigment eluted from columns of sugar or silica with 5 to 10 or 10 to 15 per cent acetone in petroleum ether and therefore exhibited a more polar nature than pheophytin- $a$. Electronic spectral data (Table 2; Figure $3 b)$ indicate a phorbin-type chromophore. That is, chlorins with intact isocyclic rings and retaining the $C$-9-conjugated keto group exhibit a Soret band with obvious inflections (overlapping bands) to the high energy side of this maximum. This contrasts with chlorins of the $e_{4}$ and $e_{6}$ type, which have cleaved isocyclic rings and exhibit essentially smooth-sided Soret absorption.

Chlorin-665, on the basis of percentages and occurrence in Site 440 samples (Table 3), appears to be an early product of the diagenetic transformation of pheophytin- $a$.

\section{Chlorin-663}

Two distinct chlorin-663 species were isolated from Leg 57 samples and exhibited site specificity in their occurrence.

\section{Site 440 Chlorin-663}

Site 440 chlorin-663 eluted from columns of sugar or silica with 10 to 25 or 25 to 50 per cent acetone in petroleum ether, respectively. This pigment exhibited increased polarity when isolated from extracts not treated with diazomethane and thus indicated the presence of a free-carboxylic acid functions(s). Electronic spectra of the native pigment and the product obtained from borohydride reduction indicate that Site 440 chlorin-663 is a chlorin tetrapyrrole with an intact isocyclic ring and a single conjugated carbonyl group, probably present as the $C-9$ keto functional. These conclusions are based on the presence of a phorbin-type Soret band, a hypsochromic shift of $17 \mathrm{~nm}$ in the red maximum (Band I), and alteration of absorption ratios of S/I from 3.3:1 to 4.9:1 and of I/IV from 6.0:1 to 3.7:1 (Table 2; Figure $3 c$ ). Similarity to a $C$-9-conjugated ketophorbin is noted from comparison to authentic phorbin pigments (see Table 2).

\section{Site 438 Chlorin-663}

Chromatographically this pigment behaved like the Site 440 isolate. Electronic spectral data and reduction with borohydride indicated the difference between the two chlorin-663 species. Native Site 438 chlorin- 663 exhibited a smooth Soret band characteristic of open isocyclic ring chlorins. The presence of at least two conjugated carbonyl groups was indicated by a $27-\mathrm{nm}$ hypsochromic shift in the position of Band I following borohydride reduction (Table 2; Figure 3d). This shift compares to one observed following reduction of purpurin-18, a conjugated diketolactone pigment (see Table 
2). Further, absorption ratios shift from $3.8: 1$ to $5.1: 1$ for $\mathrm{S} / \mathrm{I}$ and from 5.5:1 to $1.8: 1$ for $\mathrm{I} / \mathrm{IV}$, following reduction. The reduction product exhibits spectral characters reminiscent of hydroxyetiochlorins (see Table 2) and indicates that the native pigment was diagenetically formed via oxidative processes.

\section{Chlorin-660}

Chlorin-660, as isolated from sediments at Sites 438 and 440 , was quite elusive in pure form. Chromatographically this pigment exhibits very polar character requiring 50 to 100 per cent acetone in petroleum ether for elution from silica or alumina. Several isolates of a chlorin-660 exhibited less polarity, possibly indicating decarboxylation; however no trends were noted. The presence of a single conjugated carbonyl was shown via borohydride is reminiscent of pheophytin- $b /$ rhodin- $g_{7}$ behavshift in the position of the red maximum (see Table 2; Figure $4 a)$. Purification of chlorin- 660 was hampered by ultraviolet-to-blue absorbing polar impurities prohibiting further identification.

\section{Chlorin-656}

This pigment exhibited extremely polar character during chromatographic procedures, requiring acetone: $n$-propanol for elution from sugar or silica.

Electronic absorption (Table 2; Figure 4b) is indicative of a dicarbonyl chlorin with a conjugation pattern similar to chlorophyll- $b$ derivatives. The presence of $b$-series-like conjugation is noted from the presence of allow energy Soret band $(414 \mathrm{~nm})$ and a high energy red maximum $(656 \mathrm{~nm})$. Borohydride reduction elicits a hypsochromic shift of $20 \mathrm{~nm}$ in Soret position and of only $9 \mathrm{~nm}$ in the red maximum. This reaction to borohydride is reminiscent of pheophytin- $b /$ rhodin $-g_{7}$ behavior (see Table 3). Contamination of chlorin-656 with small amounts of altered chlorins is noted from the presence of absorption of approximately $690 \mathrm{~nm}$ in electronic spectra.

The nature of chlorin-656 suggests a conjugated dicarbonyl chlorin, with conjugation being opposite (e.g., Rings V-II) and therefore reminiscent of $b$-series tetrapyrroles. However, we do not claim isolation a chlorophyll- $b$ derivative here. Further, chlorin-656 does not resemble any known metallochlorins.

\section{Chlorin-636}

Chlorin-636 was detected by the presence of an absorption band (peak or inflection) at approximately 635 to $640 \mathrm{~nm}$ in electronic spectra of ethereal pigment solutions. Isolation of chlorin- 636 was based primarily upon the observation of minor coextraction from ethereal solution of this pigment with free-base porphyrin into 5 per cent $\mathrm{HCl}(w t . / v)$. Subsequently, extraction of ethereal solutions, first with 3 per cent $\mathrm{HCl}$, followed by reextraction with 7 to 10 per cent $\mathrm{HCl}$, allowed isolation of free-base porphyrin and chlorin-636, respectively, from the less basic compounds remaining in the ethereal epiphase. Chromatography on silica gel required only 1 to 2 per cent acetone in petroleum ether for elution of
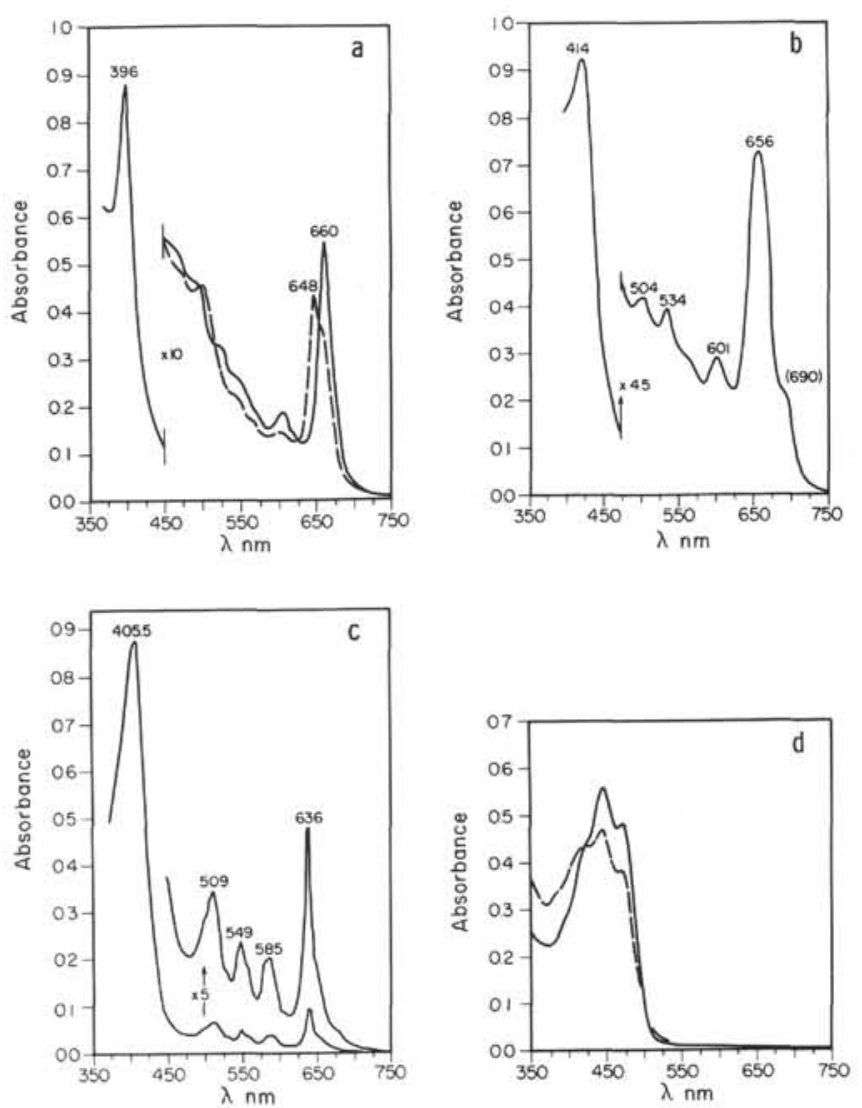

Figure 4. Electronic absorption spectra of pigments isolated from Japan Trench sediments. a. Chlorin-660 (solid line) and the product of borohydride reduction (broken line); b. Chlorin-656; c. Chlorin-636; d. $\beta$ carotene (solid line) and an unidentified oxycarotenoid (broken line). (a-c, Sites 438-440; d, Site 434.)

chlorin-636 and indicated the defunctionalized nature of this tetrapyrrole.

Electronic spectral data (Table 2; Figure 4c) obtained for chlorin-636 indicates an extremely deconjugated chlorin chromophore. Absorption maxima are 405.5, $509,549,585$, and $636 \mathrm{~nm}$, in ethyl ether solvent. Ratio of absorbancies for Soret-to-red (S/I) and Bands I to IV (I/V) are 9.4:1 and 2.2:1, respectively. These data, together with the more qualitative aspects (viz. shape) of electronic spectra, were compared with a variety of synthesized and reported chlorins. Chlorin-636 exhibits spectral and chromatographic characteristics akin to the following tetrapyrrole pigments: dihydro-DPEP $\left(\lambda_{I}=\right.$ $640 \mathrm{~nm}$ ) (Blummer and Omenn, 1961); 7-oxo-octaethylchlorin $\left(\lambda_{I}=642 \mathrm{~nm}\right)$ (Bonnett et al., 1969); dioxymesoporphyrin-IX $\left(\lambda_{I}=644 \mathrm{~nm}\right)$ and dioxydeoxophylloerythrin $\left(\lambda_{I}=640 \mathrm{~nm}\right)$ (Baker and Smith, 1974); and deoxomesopyropheophorbide- $a\left(\lambda_{I}=638 \mathrm{~nm}\right)$. The majority of the preceding pigments exhibit electronic spectra in which either the position of the Soret band is shifted to higher energy or Band III is missing, or both. Dioxydeoxophylloerythrin (dioxy-DPE) exhibits electronic absorption maxima as follows: 402, 504, 538, 580 , and $640 \mathrm{~nm}$. Ratio of Band I to IV absorption for 
dioxy-DPE is $4.6: 1$, compared to $2.2: 1$ for chlorin-636 and approximately $2.0: 1$ for dihydro-DPEP (cf. Figure $1 \mathrm{~b}$ in Blummer and Omenn, 1961).

The highest levels of chlorin-636 and free-base DPEP were found in Pleistocene samples from Site 438 (see Tables 1,2)-apparently more than a coincidence.

Though the exact nature of chlorin-636 is unknown at present, it appears that this pigment is an extremely (completely?) defunctionalized chlorin tetrapyrrole. That chlorin-636 contains oxygen, even as an hydroxy substituent in vinylic position to the central conjugated chromophore, is unlikely, since the absorption ratios (I/IV) of about 2:1 exhibited by chlorin-636 are indicative of the nonoxychlorins discussed earlier. Chromatographic behavior suggests that the 7-proprionic acid function is also absent from chlorin-636.

\section{Altered Chlorins}

In the preceding chapter by Louda and others, we forwarded an extension of past (Baker and Smith, 1973; Smith and Baker, 1974) proposals that oxidative cleavage of the isocyclic ring early in the diagenesis of chlorophyll could be a possible major pathway and lead to purpurin-like tetrapyrroles. Occurrence of these altered chlorins (purpurins) is noted in electronic spectra of chlorin isolates or mixtures for the presence of low energy absorption (approximately 680-700 nm). That these pigments are apparently not of the chlorophyll- $c$ or $-d$ series is evident for the following reasons. Pheophytin- $d$, with a red maximum at approximately 688 $\mathrm{nm}$, exhibits a bifurcated Soret with maxima at 382 and $421 \mathrm{~nm}$ (Goedheer, 1966; Holt, 1966), whereas the Soret of Leg 57 altered chlorins is typically at $408 \mathrm{~nm}$. Pheopigments derived from chlorophyll- $c$ exhibit bathochromically shifted Soret bands (approximately $421 \mathrm{~nm}$ ) and hypsochromically shifted red maxima (approximately $641 \mathrm{~nm}$ ), the latter being extremely reduced in extinction and giving the overall spectrum an etio-like appearance (see Dougherty et al., 1970; Goedheer, 1966). Bacteriochlorophylls and their pheophytins (tetrahydroporphyrins) exhibit extremely long wavelength red maxima (approximately $750-770 \mathrm{~nm}$ ) coupled with much higher energy Soret bands (approximately 368) than those occurring with dihydroporphyrin-type chlorins (e.g., Strain and Svec, 1966).

Studies with chlorins isolated from Leg 56 samples at Site 434 showed that these altered chlorins exhibit an $\mathrm{HC} 1$ number of about 18 to 20 , as does purpurin-18methylester (preceding chapter). In the present study extreme care was taken to determine the presence, or absence, of these pigments in isolates prior to diazomethane treatment. Further, methyl esterification was performed without contact with base and ethereal pigment, shown previously (preceding chapter) not to affect alteration of chlorins beyond formation of methyl esters.

In the present study altered chlorins were found to be a major constituent of the chlorin complement in sediments from Site 438 and to be present in significant amounts in Site 440 samples (see Table 3).

Chromatographic purification of these altered chlorins proved to be impossible for the present. These pigments eluted with medium to high polarity chlorins and blue-absorbing (unidentified hydrocarbon) polar impurities. Except for a very minor isolate from the Pleistocene stratum of Site 438, which contained a single red maximum at $690 \mathrm{~nm}$, the majority of altered chlorins were isolated as chlorin- altered-chlorin mixtures. That altered chlorins are either related to, derived from, or isomers of purpurin-18 is best visualized by electronic spectral comparisons (Table 2; Figure 5a). In Figure 5a the electronic spectra of purpurin-18-methyl ester is compared to a selected but representative isolate of altered chlorin. It is noticed that Soret positions match, a characteristic high energy band (approximately $365 \mathrm{~nm}$ ) is present, Band III (approximately $544 \mathrm{~nm}$ ) shows greater extinction than that of a typical chlorin, and the position of the red maximum (Band I) is bathochromically shifted $(\lambda \geq 690 \mathrm{~nm})$. The insert in Figure 5a shows the electronic spectrum $(550-750 \mathrm{~nm})$ of a more common isolate of altered chlorin as it compares to a 2:1 (A/A) synthetic mixture of known pheophorbide- $a$ and purpurin-18-methyl esters. Calculation of composition of individual chlorin species often necessitated estimation of altered chlorin and other chlorins from mixtures, assuming equal extinction. This calculation probably favored the chlorin over the altered chlorin.

In an attempt to purify an isolate of altered chlorin, a trial separation was performed with HPLC. Three main fractions were obtained from an isolate which had been chromatographed once on sugar and twice on silica without further fractionation (see Figure 5b). During this separation, a 13-minute isocratic elution with hexane:acetone $(9: 1, v / v)$ was followed by a rapidly stepped gradient to hexane:acetone $(4: 6, v / v)$ (subsequent to previous attempts at continued isochratic elution without success). The electronic spectra of these three fractions (A, B, and C) are presented for the range of 550 to $750 \mathrm{~nm}$ as insets to Figure 5c. The first, least polar fraction (A) exhibited a chlorin contaminant $(\lambda=665 \mathrm{~nm})$ and had an altered chlorin red maximum at $\lambda=692 \mathrm{~nm}$. Fraction $C$, also contaminated with chlorin, had a red maximum at $\lambda=684 \mathrm{~nm}$. On the basis of red maxima positions relative to carbonyl conjugation and observed hypsochromism due to reduction of conjugated carbonyls (viz. borohydride method) it seems likely that Fraction A (altered chlorin \#1; Table 2) is a diketopurpurin-like pigment, possibly purpurin-18. Further, Fraction C (altered chlorin \#2; Table 2) behaves chromatographically as a polar compound, which suggests an oxy-function. Derivatization of Fraction A could possibly yield a Fraction-C-like compound by partial reduction. That is, assuming Fraction $\mathrm{A}$ to be a diketone, Fraction $\mathrm{C}$ could possibly be a monohydroxymonoketo derivative of A.

\section{Tetrapyrrole-586}

This compound is commonly found as a contaminant in metalloporphyrin isolates. Polarity, as judged from chromatography, is very similar to a metalloporphyrin, yet does elute later in columns run isocratically or with only minute changes in solvent polarity. Electronic absorption, obscured for the most part, exhibits discrete 

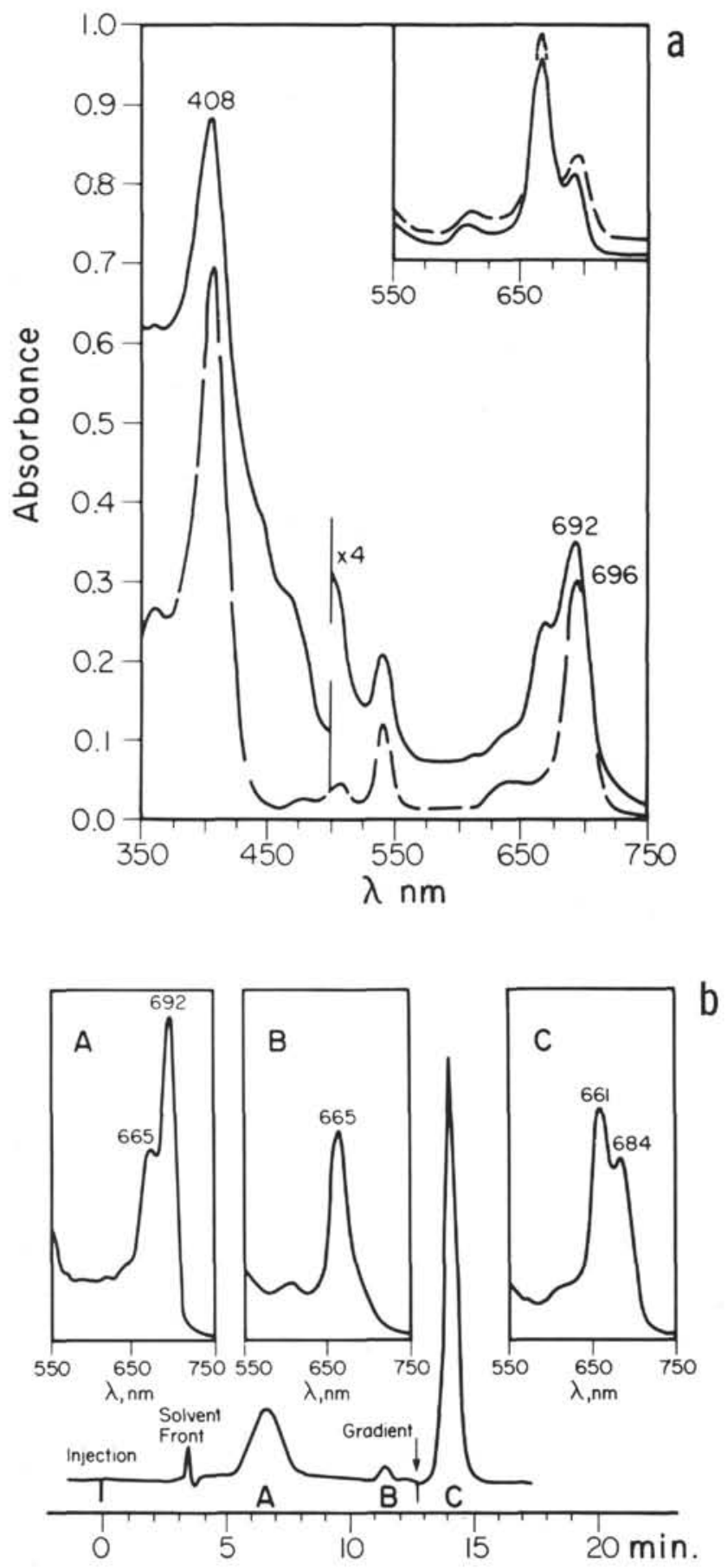

Figure 5. Altered chlorins isolated from Leg 57 sediment samples. a. Electronic spectra of altered chlorin isolated from Site 438 samples (solid line) compared with authentic purpurin-18-methyl ester (broken line). Inset shows chlorin-altered chlorin isolate from Site 440 samples (solid line) compared with a known 2:1 mixture of pheophorbide-a and purpurin-18methyl esters (broken line). b. Upper portion shows high-performance liquid chromatography of an altered chlorin isolate from Leg 57 samples. Lower portion shows low energy region of electronic spectra of HPLC isolates $A-C$. maxima at 396 and $586 \mathrm{~nm}$. Tests with borohydride on mixed isolates indicate the conversion of the 586-nm band to $558 \mathrm{~nm}$ without shifting the Soret position. A similar compound has previously been noticed in mixed metalloporphyrins and classified as nickel rhodoporphyrin (Baker and Smith, 1975). At present, on the basis of electronic absorption, tetrapyrrole 586 appears to be a phyllo- or rhodo-type porphyrin and contains at least one conjugated carbonyl function. Copper and nickel complexes of phylloerythrin (see Hodgson and Baker, 1967 ) could exhibit absorption near $586 \mathrm{~nm}$. However, Soret position of the metallophylloerythrins $(\lambda=405$ $\mathrm{nm})$ is bathochromic to that of tetrapyrrole-586 $(\lambda=$ $396 \mathrm{~nm}$ ) from Leg 57 sediments.

\section{Free-Base Porphyrins}

Free-base porphyrins were isolated from ethereal solutions exhibiting minor electronic absorption at approximately $620 \mathrm{~nm}$ by extraction into 3 to 5 per cent $\mathrm{HCl}$ (wt./v, aqueous) and subsequently purified by chromatography over alumina (III, neutral) eluting with cyclohexane:benzene $(1: 1, \mathrm{v} / \mathrm{v})$. Electronic absorption spectra were of the deoxophylloerythrinetioporphyrin (DPEP) type with maxima at 401-2, 500-5, (535-7), $575-7$, and $620 \mathrm{~nm}$ (Table 2). Mass spectra of a freebase isolate from Section 438A-4-4 yielded parent ions at $\mathrm{m} / \mathrm{e} 476,462,448$, and 434 , in decreasing abundance. These correspond to C-32, 31, 30, and 29 DPEP. The distribution of molecular weights is similar to free-base porphyrins isolated from previous sediment samples (e.g., Baker et al., 1977, and references therein) and represents a dealkylated series.

The occurrence of DPEP in Pleistocene sediments at only 47 meters sub-bottom must assuredly indicate sediment reworking. The Pleistocene stratum at Site 438 is noted as being of sand-rich terrigenous origin (von Huene, Nasu, et al., site chapter, this volume, Pt. 1). Resedimentation from the Pliocene-Miocene outcrop landward of Site 438 where block-faulting has occurred (see von Huene, Nasu, et al., 1978, Figure 3) could explain the occurrence of DPEP in such otherwise geologically young sediments.

\section{Metalloporphyrins}

Metalloporphyrins were isolated from nonpolar (unidentified hydrocarbon) fractions during sugar and silica chromatography. Subsequent rechromatography on alumina, developed with cyclohexane and cyclohexane: benzene $(1: 1, \mathrm{v} / \mathrm{v})$, afforded purification of metalloporphyrin isolates. Metalloporphyrins were isolated from samples ranging in sub-bottom depth from 532 to 676 meters and from 354 to 778 meters for sediments from Sites 438 and 440 , respectively (see Table 3 ).

Electronic spectra (Table 2) of metalloporphyrin isolates indicate the predominance of copper porphyrins. Absorption maxima, in ethyl ether, were 393-5 (Soret), $520(\beta)$, and $556(\alpha)$ nanometers. Ratios of absorbancy of $\alpha$ to $\beta$ bands ranged from 1.92:1 to $2.05: 1$ and yielded a mean $(\bar{x})$ of 2.03:1. This compares to mixtures of synthetic copper etioporphyrin I with absorption maxima 
of 399,527 , and $564 \mathrm{~nm}$ and nickel etioporphyrin I with maxima at 395,514 , and $552 \mathrm{~nm}$. Metalloporphyrins isolated from Leg 57 samples thus yielded intermediate electronic spectra indicative of copper-nickel porphyrin mixtures.

Mass spectra were determined on all metalloporphyrin isolates and indicated complex mixes of copper and nickel DPEP and etioporphyrins. However, extremely minute amounts of final isolate coupled with high concentrations of higher molecular weight nonporphyrin species hampered interpretation. Sample 440B-46-3 yielded a metalloporphyrin isolate of sufficient purity for mass spectral interpretation. The sample contained an elaborate mixture of copper and nickel etioporphyrins and DPEP porphyrins. Presented in Table 4 is the distribution of parent ions on the basis of carbon number and metallo series, intensities being normalized values adjusted for overlapping contribution from the bi-isotopic metals.

The predominance of dealkylated copper etioporphyrins is obvious from the mass spectrum of metalloporphyrins isolated from Section 440B-46-3. The occurrence of copper porphyrins is taken as an indicator of terrigenous detrital input. Discussion of copper porphyrins in deep sea sediments and of their utilization as indicators of oxidized terrestrial material appears elsewhere (Palmer and Baker, 1978). Finding copper porphyrins in sediments from Site 440 is consistent with preliminary on-board analyses that interpreted the landward slope of the Japan Trench as being derived from an "apron of downslope terrigeneous sediment" (von Huene, Nasu, et al., site chapter, this volume, Pt. 1).

\section{Tetraterpenoids Isolated from Leg 56 Sediments}

Analyses of Section 434-1-3, a Pleistocene sediment sample at 4 meters sub-bottom, led to the isolation of two carotenoid pigments. An oxycarotenoid, reported in the preceding chapter, was found to be mainly responsible for obscuring the electronic spectra of intermediate polarity chlorins. Further analysis led to the isolation of a hydrocarbon carotenoid identified as $\beta$-carotene on the basis of chromatographic, hexane: 90

TABLE 4

Mass Spectral Data for Copper-Nickel Porphyrin Isolates from Section 440B-46-3

\begin{tabular}{cccccccc}
\hline Series & C-26 & C-27 & C-28 & C-29 & C-30 & C-31 & C-32 \\
\hline Nickel DPEP & - & - & - & - & 504 & 518 & ind. \\
& & & & & $(32)$ & $(24)$ & \\
Nickel etio & 450 & 464 & 478 & 492 & - & - & - \\
& $(59)$ & $(50)$ & $(46)$ & $(32)$ & & & \\
Copper etio & 455 & 469 & 483 & 497 & 511 & - & - \\
& $(100)$ & $(86)$ & $(68)$ & $(36)$ & $(24)$ & & \\
Copper DPEP & - & - & - & 495 & 509 & 523 & 537 \\
& - & - & - & $(18)$ & $(32)$ & $(48)$ & $(45)$ \\
\hline
\end{tabular}

Note: Normalized intensities relative to the most abundant $(\mathrm{C}-26 \mathrm{Cu}$ etio) ion; ind. = indicated. Major isotopes only are listed, in each case a $(\mathrm{M}+2)^{+}$ion corresponding to the higher mass isotope was observed. (Isotope abundance: $\mathrm{Ni}^{58}=67.8$ per cent, $\mathrm{Ni} 60=$ 26.2 per cent $; \mathrm{Cu} 63=69$ per cent, $\mathrm{Cu} 65=31$ per cent.) per cent methanol partition, and spectral characteristics. Electronic spectra of $\beta$-carotene and the unidentified oxycarotenoid isolated from Section 434-1-3 are given in Figure $4 \mathrm{~d}$. $\beta$-carotene exhibited maxima at 449 and 475 and an inflection at $425 \mathrm{~nm}$ in $n$-hexane solvent. Chromatography on activated (Grade I) neutral alumina required only 0.5 to 1.0 per cent acetone in petroleum ether for elution. $\beta$-carotene was entirely epiphasic to $n$-hexane:90 per cent methanol partition. Physiochemical behavior is identical to $\beta$-carotene isolated from Spinacea oleracea and published criteria (Batra et al., 1973; Foppen, 1971). Discussion of carotenoids in deep sea sediments was included in our studies in the preceding chapter and its references of pigments in Japan Trench sediments.

\section{SUMMARY AND CONCLUSIONS}

Leg 57 represents the second half of an investigation on Japan Trench and adjacent sediments. Analyses of tetrapyrrole pigments were performed on samples from Sites 438, 439, and 440.

Sites 438 and 439 , essentially a single site, are located near the convergence of the landward deep sea terrace and upper trench slope. The area of Sites 438 and 439 is a subsided ancient landmass (Oyashio) which has been at bathyal depths since the Miocene. Site 440 is located in the midslope terrace and consists of downslope terrigenous sediment with ponding of shelf-derived turbidites in the Pleistocene strata (see Site Chapter, Site 440, this volume, Pt. 1).

Yield of tetrapyrrole pigment, as a component of the organic carbon fraction, is traced by the generation of a pigment yield index, or PYI. In the preceding chapter we related pigment yield of sediment, wet weight, to percentage of organic carbon, dry weight. Presently PYI is corrected to sediment, dry weight. The corrected PYI (viz. PYI-dry) allows better visualization of trends between sites, especially from such highly consolidated sediments as at Site 440. $\mathrm{A}$ rapid demise $(\triangle \mathrm{PYI}=$ $-1.2 / 100 \mathrm{~m}$ ) in tetrapyrrole pigments was noted in the Pleistocene stratum at approximately 250 to 300 meters, followed by a slower loss rate $(\triangle P Y I=-0.2 / 100 \mathrm{~m})$ in more deeply buried (geologically older) sediments, at approximately 300 to 780 meters, from Site 440 .

That a major pathway of chlorophyll diagenesis in deep sea sediments leads to removal rather than preservation of tetrapyrrole pigments from the fossil record is obvious from the present and past studies (see preceding chapter; Orr et al., 1958; Swain et al., 1964).

In regions where the sediment-water interface is below the photic zone, the initial form of tetrapyrrole input is pheophytin (see Orr et al., 1958; Yentsch, 1965). Loss of pheophytin, and its derivatives is apparently controlled by oxidation in the water column and at the sediment/water interface and by establishment of a negative Eh with burial (see Kemp and Lewis, 1968; Koyama et al., 1968; Orr et al., 1958). At Site 438, input of terrestrial material, sediment reworking, and oxygenated bottom waters apparently led to an initial rapid demise of chlorophyll derivatives along with generation of large quantities of altered chlorins. Altered chlorins ap- 
pear to be purpurin-like pigments generated by oxidative cleavage of the isocyclic ring of pheopigments. The chlorin array isolated from Site 440 samples indicates competition between reductive and oxidative diagenetic modes. Preservation of pheophytin- $a$ to 456 meters subbottom, coupled with the coincidence of altered chlorins, suggests this interplay of oxidation-reduction pathways. The stabilization of the phytyl ester linkage of pheophytin- $a$ is attributed to a reduction of the phytyl double bond, generating dihydrophytol pheophorbide- $a$, which prevents elimination of phytol as neophytadiene and forces dephytylation to proceed by a hydrolytic mechanism under more highly stressed conditions (cf. Baker, 1970; Baker and Smith, 1974). Elimination of phytol as neophytadiene prior to-or, more likely, following-oxidative cleavage of the isocyclic ring would then lead to a second series of chlorins (viz. purpurins). The mixture of pheophytin- $a$, as well as other phorbins, with altered chlorins indicates an initially oxic environment, or oxic input through reworking, coupled with the rapid establishment of a reducing environment. The absence of pheophytin- $a$ from sediments at Site 438 supports these arguments.

Following initial deposition, reworking, and relative stabilization of sediment, increased defunctionalization of chlorophyll derivatives occurs. Reduction of ringconjugated groups leads to a decrease in the position of chlorin red maxima (Band I) with increasing depth, subbottom. Conjugated carbonyl groups, usually present as C-9 keto, $\gamma$-glycoxylate, or C-6, $\gamma$-diketolactone substituents, were shown to survive to 722 meters sub-bottom in sediments from Site 440 . The defunctionalization of keto groups is most likely hindered in the sediment profile at Site 440 by an extremely low thermal gradient (less than $1^{\circ} \mathrm{C} / 100 \mathrm{~m}$; site chapter, this volume, Pt. 1).

The occurrence of dealkylated copper etioporphyrins as the major component of a metalloporphyrin isolate (Sample 440B-46-3) indicated input of preoxidized terrestrial matter (cf. Palmer and Baker, 1978). The isolation of DPEP-type free-base porphyrins from the Pleistocene stratum of Site 438 sediments is attributed to sediment-reworking.

In conclusion, it now becomes more apparent that the diagenesis of sedimentary chlorophyll (viz. pheophytin) is ultimately controlled by the degree of interaction of two main pathways. Rapid sedimentation, reducing conditions, and sediment stability lead to a reduction-thermal stress pathway wherein DPEP-porphyrins are generated and then thermally altered to yield deand transalkylated metallo-DPEP-etio mixtures. Conversely, sediment reworking, oxic conditions, and input of coarse-grained sediment leads to initial formation of oxidized tetrapyrroles, such as purpurins and the chlorin- $e$ and $-p$ series, followed by essentially complete removal from the fossil record by presently unknown mechanisms. Although input of terrigenous material complicates this simplistic view, the presence of copper etioporphyrins in such sediments affords a handle by which such processes can be recognized.

Leg 58 sediments now under study appear to offer added elucidation of the oxidative (purpurin) pathway, and samples from Legs 63 to 65 should provide further insight concerning reductive processes.

\section{ACKNOWLEDGMENTS}

This research was funded by the Oceanography Section of the National Science Foundation under grants OCE7412438A02 and OCE77-07273. We thank Dr. Charles Sweeley and Mr. Bernd Soltmann of the Michigan State University, Department of Biochemistry Mass Spectrometry Facility, for determination of field and electron-impact desorption mass spectra and for their hospitality; the Milton Roy Company, Laboratory Data Control Division, and Mr. Phil DeLand for training and access to high performance liquid chromatography; Dr. Susan Palmer for assistance in deconvolution of mass spectra of copper-nickel metalloporphyrin mixtures; $\mathrm{Mr}$. Ed McKnight for fabrication of a nitrogen gas chamber for sample loading of thin-layer chromatograms; Ms. Debra Murphy for technical assistance; and Drs. Kenneth Winters and Eugene $\mathrm{H}$. Man for their review of the manuscript.

\section{REFERENCES}

Baker, E. W., 1970. Tetrapyrrole Pigments. In Bader, R. G., Gerard, R. D., et al., Init. Repts. DSDP, 4: Washington (U.S. Govt. Printing Office), 431-438.

Baker, E. W., and Palmer, S. E., 1978. Geochemistry of porphyrins. In Dolphin, D. (Ed.), The Porphyrins (Vol. I): New York (Academic Press), 485-551.

Baker, E. W., Palmer, S. E., and Huang, W. Y., 1977. Intermediate and late diagenetic tetrapyrrole pigments, Leg. 41: Cape Verde Rise and Basin. In Lancelot, Y., Seibold, E., et al., Init. Repts. DSDP, 41: Washington (U.S. Govt. Printing Office), 825-837.

1978. Chlorin and porphyrin geochemistry of DSDP Leg 40 Sediments. In Bolli, H. M., Ryan, W. B. F., et al., Init. Repts. DSDP, 40: Washington (U.S. Govt. Printing Office), 639-647.

Baker, E. W., and Smith, G. D., 1973. Chlorophyll derivatives in sediments, Site 147. In Heezen, B. C., MacGregor, I. D., et al., Init. Repts. DSDP, 20: Washington (U.S. Govt. Printing Office), 943-946.

1974. Fossil porphyrins and chlorins in deep ocean sediments, II. Preprints, Symp.-Div. Petrol. Chem. Am. Chem. Soc., 19, 744-768.

1975. Chlorophyll derivatives in DSDP Leg 31 Sediments. In Karig, D. E., Ingle, J. C., Jr., et al., Init. Repts. DSDP, 31: Washington (U.S. Govt. Printing Office), 629632.

Batra, P. P., Gleason, R. M., and Louda, J. W., 1973. Cyclization of lycopene in the biosynthesis of $\beta$-carotene. Phytochem., 12, 1309-1313.

Blummer, M., and Omenn, G. S., 1961. Fossil porphyrins: Uncomplexed chlorins in a Triassic sediment. Geochem. Cosmochim. Acta, 25, 81-90.

Bonnett, R., Dimsdale, M. V., and Stephenson, G. F., 1969. The Meso-reactivity of porphyrins and related compounds. Part Iv. Introduction of oxygen functions. J. Chem. Soc. (c), 564-570.

Candlin, J. P., and Rennie, R. A. C., 1973. Reduction Methods. In Bentley, K. W., and Kirby, G. W. (Eds.), Techniques of chemistry Vol. IV. Elucidation of Organic Structures by Physical and Chemical Methods, Part II: New York (Wiley), 77-135.

Dougherty, R. C., Strain, H. H., Svec, W. A., Uphaus, R. A., and Katz, J. J., 1970. The structure, properties and distribution of chlorophyll c. J. Am. Chem. Soc., 92, 28262833. 
Fischer, H., and Stern, A., 1940. Die Chemie des Pyrrols. Pyrrolfarbstoffe (Vol. 2, Pt. 2): Leipzig (Akademische Verlagsesellschaft), 84-120.

Foppen, F. H., 1971. Tables for the identification of carotenoid pigments. Chromatogr. Rev., 14, 133-298.

Fuhrhop, J. H., and Smith, K. M., 1975. Laboratory methods. In Smith, K. M. (Ed.), Porphyrins and Metalloporphyrins: Amsterdam (Elsevier), pp. 757-869.

Goedheer, J. C., 1966. Visible absorption and fluorescence of chlorophyll and its aggregates in solution. In Vernon, L. P., and Seely, G. R. (Eds.), The Chlorophylls: New York (Academic Press), pp. 147-185.

Hajibahim, S. K., Tibbetts, P. J. C., Watts, C. D., Maxwell, J. R., Eglinton, G., Colin, H., and Guiochow, G., 1978. Analysis of carotenoid and porphyrin pigments of geochemical interest by high-performance liquid chromatography. Anal. Chem., 50, 549-553.

Hodgson, G. W., 1973. Geochemistry of porphyrins - Reactions during Diagenesis. Ann. N. Y. Acad. Sci., 206, 670684.

Hodgson, G. W., and Baker, B. L., 1967. Spectra of selected geochemically significant porphyrins and chlorins. Chem. Geol., 2, 187-198.

Holland, J. F., Soltmann, B., and Sweeley, C. C., 1976. A model for ionization mechanisms in field desorption mass spectrometry. Biomed. Mass Spectrom., 3, 340-345.

Holt, A. S., 1959. Reduction of chlorophyllides, chlorophylls and chlorophyll derivatives by sodium borohydride. Plant Physiol., 34, 310-314.

1966. Recently characterized chlorophylls. In Vernon L. P., and Seely, G. R. (Eds.), The Chlorophylls: New York (Academic Press), pp. 111-118.

Kemp, A. L. W., and Lewis, C. F. M., 1968. A preliminary investigation of chlorophyll degradation products in the sediments of Lakes Erie and Ontario. Proc. 11th. Conf. Great Lakes Res., pp. 206-229.
Koyama, T., Shimomura, O., and Yanagi, K., 1968. Vertical distribution of pigments in a lake sediment as determined by paper chromatography. Geochem. J., 2, 87-103.

Kvenvolden, K. A., personal communication.

Orr, W. L., Emery, K. O., and Grady, J. R., 1958. Preservation of chlorophyll derivatives in sediments off Southern California. Bull. Am. Assoc. Petrol. Geol., 42, 925-962.

Palmer, S. E., and Baker, E. W., 1978. Copper porphyrins in deep-sea sediments: A possible indicator of oxidized terrestrial organic matter. Science, 201, 49-51.

Seely, G. R., 1966. The structure and chemistry of functional groups. In Vernon, L. P., and Seely, G. R. (Eds.), The Chlorophylls: New York (Academic Press), pp. 67-110.

Smith, C. D., and Baker, E. W., 1974. Chlorophyll derivatives in DSDP Leg XXII Sediments. In von der Borch, C. C., Sclater, J. C., et al., Init. Repts. DSDP, 32: Washington (U.S. Govt. Printing Office), 677-679.

Soltmann, B., Sweeley, C. C., and Holland, J. F., 1977. Electron impact ionization mass spectrometry using field desorption activated emitters as solid sample probes. Anal. Chem., 49(8), 1164-1166.

Strain, H. H., 1958. Chloroplast pigments and chromatographic analysis. 32nd Annual Priestly Lectures, Pennsylvania State University, University Park.

Strain, H. H., and Svec, W. A., 1966. Extraction, separation, estimation, and isolation of the chlorophylls. In Vernon, L. P., and Seely, G. R. (Eds.), The Chlorophylls: New York (Academic Press), pp. 22-66.

Swain, F. M., Paulsen, G. W., and Ting, F. 1964. Chlorinoid and flavinoid pigments from aquatic plants and associated lake and bay sediments. J. Sed. Petrol., 34, 561-598.

Triebs, A., 1936. Chlorophyll-und Häminderivate in organischen Mineralstoffen. Angen. Chem., 38, 682-686.

von Huene, R., Nasu, N., et al., 1978. On Leg 57: Japan Trench transected. Geotimes, 23, 16-21.

Yentsch, C. S., 1965. Distribution of chlorophyll and pheophytin in the open ocean. Deep-Sea Res., 12, 653-666. 